\title{
Bracing for and Embracing Difference \\ in America's Majority Minority Metropolis: \\ Bangladeshi Immigrant Children \\ Coming of Age in New York City
}

\author{
"What is barely hinted in other cities is condensed and enlarged in New York" Saul Bellow \\ Cited in Mollenkopf \& Castells (1991) \\ M. Faridul Alam, Ph.D. \\ The Graduate Center, City University of New York \\ New York, NY
}

\section{Research problem}

Despite an array of pioneering studies (Kasinitz, Molenkopf, Waters \&

Holdaway, 2008; see Kasinitz, Mollenkopf, Waters, 2004) on how the second generation immigrant New Yorkers are incorporating in arguably the most diverse and multicultural setting in the US, characterized by the absence of any dominant majority, some of the most visible and vibrant ethnic communities in the metropolis continue to remain underrepresented. For example, very little is known about the increasingly large number of South Asian children from Bangladesh, who immigrated with their parents since the early 1990s as beneficiaries of the newly enacted Diversity Visa (DV) Lottery Program, or were born and raised in this gateway city. Organizing principles to conceptualize the acculturation patterns of the children of non-European immigrants in this era could be derived from the interpretive paradigms and polarities which evolved in the wake of a demographic transformation in the country brought about by the Immigration and Nationality Act of 1965 (The Hart-Cellar Act) or P.L. 236, with an influx predominantly from the Asian, Caribbean and Latin American sending countries, famously known as the Second Great Wave of US immigration. Evidently, this paradigmatic shift in ethnic diversity countervailed the conventional wisdom of canonical classical assimilation theories premised on the experiences of the First Great Wave of largely Northern and Western European immigrants from 1880 through 1920, captured by the meta-narrative of "E Pluribus Unum," calling for an end of difference or plurality of origin to embrace the unity of an "imagined community" (Anderson, 1983). 
The 1990s were particularly marked by the resurgence of research on the impact of post-1965 immigration to the US together with a widespread popular sentiment against illegal immigration reflected in California's Proposition 187, a 1994 ballot initiative designed to deny illegal immigrants social service, health care, and public education, and Proposition 227, a 1998 anti-bilingual education ballot initiative and Arizona's proposition 203, a 2000 ballot initiative banning bilingual education. Anthropologists, historians, sociologists, and political scientists rekindled their interest in the acculturation of new immigrants, whose difference of origin, ethnicity and phenotype questioned the salience of unidirectional and irreversible "melting pot" (Zangwill, 1925), "straight-line" (Warner and Srole, 1945) theories of classical assimilation rendering the "race relations theory” (Park \& Burgess, 1924) propounded by the Chicago School of Sociology obsolescent if not obsolete. Incipient postulations accounting for the atypical experiences of children of non-European immigrants, reflected in the analogies of "beyond the melting pot” (Glazer \& Moynihan, 1963), "spatial assimilation” (Massey \& Denton, 1985), "bumpy line approach” (Gans, 1992), "second generation decline,” (Gans, 1992), "unmelted pot” (Mollenkopf \& Castells, 1991), questioning "Is Assimilation Dead?” (Glazer, 1993) or “Assimilation today: Is One Identity Enough?” (Glazer, 1993) eventually culminated in a more comprehensive mid-level theoretical framework of "segmented assimilation” (Portes \& Zhou, 1993; Portes \& Rumbaut, 2001). This theory suggests three patterns of intergenerational acculturation, two of which have variants. "Consonant Acculturation" signifies intergenerational harmony and straight-line assimilation, but its variant "Consonant Resistance to Acculturation" portends its mirror image in which regression \& fixation to native culture result in marginalization and downward mobility of both generations. "Dissonant Acculturation-Type I" illustrates ruptured family ties, caused by the rejection of native culture by immigrant children, under the adverse influence of inner city subculture, where the parents adapt through increased involvement with their ethnic enclave. However, "Dissonant Acculturation -Type II," its counterpart, illuminates exacerbated intergenerational conflict and second generation decline, prompting the parents to withdraw even from ethnic affiliations. "Selective Acculturation" is an expedient mode of acculturation without assimilation intended to secure upward mobility for the second generation immigrants by strategically balancing the conflicting demands of continuity and change. Transnationalists gave a different spin to this debate by emphasizing on dissimilation, instead of assimilation, of immigrants through simultaneity of "transnational social field" and "deterritorialized national identity" (Levitt \& Schiller, 2004; Levitt \& Waters, 2002). The revivalist school (Foner, 2006; Alba \& Nee, 2003; Waldinger \& Feliciano, 2003) critiqued "Segmented Assimilation" theory by debunking the myth of "straight line assimilation" with renewed historical and sociological insights and reframing the argument structure of "dissonant acculturation" in light of the positive changes in race relations in the US after the Civil Rights Movement of the 1960s. It dismissed transnationalism as an essentially first 
generation phenomenon. However, cavalier attempts to reinvent the classical assimilation theories to contest the emerging interpretive frameworks generated mixed results at best, legitimizing more nuanced understanding of ethnic communities through new studies grounded in their situated experiences. The widening gaps between a constellation of emerging theories of acculturation on new second generation immigrants on the one hand and the findings of a growing body of empirical research on the other also demanded more context specific episteme and praxis.

\section{Research background}

The three intertwined research questions for this study were: how the children of Bangladeshi immigrants braced for and embraced acculturation in New York City as they came of age; how their acculturative experiences were shaped by the parental influences intended to retain the native culture; and how the push-pull factors between the two generations were actually played out in the lives of the children. The first question represented change, discontinuity and flux, and the second question signified continuity and fixity, while the third question focused on the interplay between continuity and change in the lives of immigrant children. The second generation experiences are particularly critical in understanding immigrant acculturation patterns because the first generation migrants generally turn out to be the "birds of passage haunted by the dreams of return” (Portes, 2004. p. 157) to the native county, unlike their descendants who are in the host country to stay (Portes, 2004). Kasinitz, Waters, Mollenkopf, \& Anil (2002) cogently argue that the children of immigrants symbolize an analytical category to gauge the distance of this age cohort from the native county; to measure its exposure to acculturation in the host country; and to capture its transition within a historical timeframe. Nonetheless, lack of intergenerational perspective in existing studies on immigrant acculturation (Gans, 2000) forecloses bifocality and dual tracking precluding the possibility of insights into the gains and losses of the second generation immigrants vis-à-vis their parents.

\section{Methodology}

This exploratory study drew upon the lived experiences of thirty three Bangladeshi boys and girls, between the ages of sixteen and twenty four. They lived in four boroughs of New York City: Brooklyn, Queens, Staten Island and the Bronx. Twenty five of these informants immigrated with parents before the age of ten (G-1.5), while eight were born and raised in the US (G-2.0). Storied narratives of their coming of age in the majority minority metropolis and acculturation were captured through in-depth interviews, which were triangulated with observations of parent-child interactions in their home environments in conjunction with informal discussions between me and twenty five 
parents, before and after the interviews with their children. Consistent with the tradition of grounded theory, a range of contested theories of immigrant acculturation, enunciated in the post-1990 era, including but not limited to "segmented assimilation theory," "second generation decline" and "second generation advantage” (Kasinitz et al, 2008) were deployed as sensitizing concepts to organize complex experiences of the informants at the initial stage of inquiry. The data analyses transitioned from the surface structure immersion through open coding, axial coding and select coding to the deep structure immersion by means of theoretical memoing and sampling. Major themes and patterns that finally emerged from the convergence of qualitative data analyses were developed into four analytic frameworks representing collective experiences "beyond the mediated experience of the situated individual” (James, Hockey \& Dawson, 1997.p 9-10).

Serendipitously, my status as an ethnic immigrant father and husband played a pivotal role in gaining access to Bangladeshi families, especially with the female children eligible for the study. In what turned out to be a culturally competent family-to-family approach, the parents required me and my wife to eat either lunch or dinner with their families, as a prelude, if not a precondition, for each interview with their son or daughter. During the time I conducted the interview with an informant in a separate room, my wife kept the parents busy by socializing with them. Subsequently, I engaged the parents in informal discussion, which always proved to be more than a mere epilogue. This strategy allowed me to stay at the family's home longer, gain the parents' trust, establish greater rapport with their children, and observe the parent-child interactions in their natural setting without being intrusive, in effect, affording unforeseen opportunities for accessing cross-generational vantage points to ground the study.

\section{Results}

The four analytic frameworks derived from this study were: crossroads of acculturation between the two generations; gendered socialization in patriarchal families; Big Apple at the center stage of transformation; and construction of post-immigrant self identities as the children came of age.

\section{Crossroads of acculturation: Delicate dance over continuity and change}

The immigrant parents and their children structured their experiences through powerful narratives representing a crossroads of acculturation. With the onset of adolescence, the second generation Bangladeshi immigrants began to outgrow the influences of primary socialization with their parents, encoded and emplotted by the framing narrative of retention of native culture, through secondary socialization with fellow students and multiethnic friends from public schools and inner city neighborhoods. Their intentionality to transition from one mode of socialization to another was particularly poignant when it came to self-othering or distancing from their ethnic 
enclave, unlike the parents, who were perpetually anchored in it as a sanctuary to validate the norms of primary socialization among children, resulting in a growing acculturation gap dividing the two generations. The two storylines of adaptation in the metropolis generated contrasting analytical categories for ethnographic inquiry. The leitmotif of parents' storyline was dislocation and dispersion from the common origin, prompting the need for the restoration of lost heritage through a deterritorialized Diaspora to be consolidated by intergenerational transmission of native culture in a "redemptive journey" (Krisna, 1999). If the parents were driven by the structure of collective history, with a putative beginning embedded in the past, their children were propelled by the agency of genealogy, marked by a "discontinuous (and) local" (Foucault cited in Smart, 1997), beginning (re)constructed retrospectively. Attempts by the parents to foreground intergenerational continuity, intended to forestall attrition of native culture among their descendants, were pitted against the children's dominant theme of bracing for and embracing change through discovery upon arrival in the host country, generating daunting challenges for building any bridge between the two increasingly irreconcilable discourses. Even if the parents signed off on selective acculturation for their children, as long as they did not reject the native culture altogether, to facilitate their academic success, the intricate dance between the two generations over finessing the needs of continuity against change continued apace. However, when the prospects for successfully straddling the two discourses dwindled among children, in some cases setting in motion the traits of "dissonant acculturation" precipitating a declining trajectory, the parents either sought refuge in the ethnic enclave or withdrew from both native and host cultures in desperation.

\section{Gendered socialization in patriarchal value system: A site of resistance}

Bangladeshi immigrant mothers played a pivotal role in inculcating the values of patriarchal norms, particularly among their daughters, who were expected to be the purveyors of intergenerational cultural continuity. Intriguingly, unequal and gendered parental expectations created equal opportunity disadvantages for both male and female children. The boys enjoyed greater freedom from parental supervision, oftentimes at the risk of being more exposed to the street culture. Conversely, the girls benefitted from more stringent parental regulation to focus better on educational and career objectives. In families with children of both sexes, the boys were generally encouraged to make more challenging career choices than the girls. However, unlike the girls, the boys were required to take over the responsibility of the family when the father, or the primary breadwinner, had a disability or life-threatening condition, even if it compromised their high school or college education. Regardless of their unequal opportunities, gendered socialization, and in some instances even sexual division of labor, the more acculturated girls empowered by their secondary socialization in school, affiliation to egalitarian society and educational success to expressed stronger voice of dissent against arranged marriage and claimed greater latitude of autonomy in their career choices, unlike the boys 
who preferred to remain coy. In other words, instead of accepting the gender role, encoded in patriarchal value system, as destiny they transformed it as a site of resistance, contestation, and negotiation in order to (re)inscribe "Ecriture feminine," or female writing, against the privileged discourse to improve parity. At times, illustrating a role reversal in a pre-figurative mode of transmission, from the child to the parent, as opposed to post-figurative transmission, from the parent to the child, some of these girls even influenced their mothers to start rejecting the silence of the subaltern.

\section{Big Apple at the center stage of transformation: A Tale of Two Cities}

The two generations of Bangladeshi immigrants were in the process of remaking the Big Apple with contrasting outcomes as it were "A Tale of Two Cities." To the parents the heterogeneous and multicultural context of reception signified displacement from the homogenous country of origin, demanding reinvention and replacement through the niche of ethnic enclaves in a burgeoning Diaspora that would effectively tilt the odds of demographic landscape and diversity of an "unmelted pot” (Mollenkopf \& Castells, 1991) in their favor. However, their children resorted to self-othering from homogenizing affiliations with ethnic enclaves prospectively upending the Diaspora. They construed the metropolis as a palimpsest by (de)(re)inscribing heterogeneous affiliations to be incorporated with other immigrant children as new New Yorkers. Ethnic pluralism, or the absence of any dominant majority in the city, created a dynamic context for them in which the boundary between the center and the margin became blurred and the center itself turned marginal (Minn-Ha, 1991). In a dialogic interaction with the Big Apple which emerged as the lead character (akin to Dickens' London and Joyce's Dublin) transcending a variegated context, they continued to remake the city as the center stage of their own transformation, reflected in their bridging relationship with cohorts from many different ethnic, racial and national origin. Conversely, their parents fell back on bonding relationships within their ethnic community network. Simply put, in a narrative tour de force valorizing dialogic interaction the Big Apple remade the children of Bangladeshi immigrants as much as they remade the Big Apple, regardless of its reputation as more than a dual city with a complexity of inequality unparalleled by any other place in the US (Mollenkopf \& Castells, 1991). However, their parents remained impervious to the feedback loop and synergistic relationship with the metropolis. Interestingly, some informants identified their multicultural "New Yorker," identity as marginalized in comparison with the core "White American" identity, external and marginal to New York City, the center of their globalized or glocalized world.

\section{Construction of post-immigrant self-identities: Trajectory and repertory}

While the parents remained safely anchored in their primordial national origin ("Bangladeshi”) identity to cope with the changes brought about by the life-world in the host country, their children embraced changes by carving out compatible and exploratory post-immigrant identities represented by both trajectory and repertory. The 
trajectory represented a paradigmatic movement away from an unhyphenated parental self-identity ("Bangladeshi”) to more acculturative hyphenated identities ("BangladeshiAmerican," "Bangladeshi-Muslim-American,” or “Asian-American”) and/or unhyphenated ("American”/“NewYorker”). However, the paradigm shift on the trajectory made more acculturated self-identities incommensurable with less acculturated identities. However, in the complex identity repertoire ("Russian doll," "Juggler," "Many hats on the same head," "Palimpsest not a stone tablet") on a syntagmatic dimension multiple old and new identities were simultaneously processed by code switching among various subject positions, illustrating the "second generation advantage" (Kasinitz et al 2008), Which enabled them to reintegrate the new with the old, unlike the irreversible and unidirectional "straight line" assimilation that required an inevitable forfeiture the old. Although the identity trajectory was not premised on identity repertory, complex identity repertory was contingent upon extended identity trajectory. The trajectory was illustrated by a succession of vertical lines, while the repertory was exemplified as a straight line cutting across the trajectory and a spiral from its beginning to the end. Evidently, some informants were more adroit than others in constructing and negotiating their post-immigrant identities, "a syncretic world of ethnicity rather than a world of discrete culture and tradition" (Fisher, 1986). However, the seemingly progressive de-essentialization and hybridization of identities in this process always had "a local habitation and a name," to borrow from the Bard, grounded in New York City. The difference that they embraced in the majority minority metropolis was without any semblance of Derridean "differ(a)nce," in which a perpetual interplay between deferment and difference evoked or subverted an illusion of presence or identity (Johnson, 1980).

\section{Mid-level theories proposed in the study}

Four mid-level theories have been proposed in this study. The first and second generation Bangladeshi immigrants in New York City are engaged in a delicate dance over continuity and change in a modus operandi of "selective acculturation;" if and when it breaks down they tend to wade into an intergenerational fray epitomizing "dissonant acculturation." Unequal expectations embedded in patriarchal value system create equal opportunity disadvantages for both boys and girls, while acculturated girls transform gendered socialization into a site of resistance against hegemony. The two generations of immigrants turn the majority minority metropolis into a "Tale of Two Cities;" the parents add more to its margins, but the children are instrumental in blurring the boundaries between its imagined center and the margins transforming New York City as new New Yorkers as the city, as a character beyond its context, transforms them in a constant feedback loop which is unavailable to the parents. Unlike their parents, who are perpetually anchored in pre-immigrant primordial identity, the children carve out postimmigrant self identities as both repertory and trajectory (Table $1 \&$ Table 2) to brace for and embrace difference the city continues to thrive on. 


\section{Utility for social work practice}

Since social work is historically considered as a policy based practice it is incumbent upon the practitioners to be fully conversant with evolving immigration policies in the US as they impinge upon understudied ethnic immigrants. Culturally competent praxis requires critical understanding of the paradigm shift in acculturation theories accounting for the unique experiences of the "unmeltable" immigrants and their descendants. The bifocal thrust of the study reveals how the homeostasis of parent-child subsystem in the family structure hinges on a delicate dance over continuity and change between the two generations finessing the modus operandi of "selective acculturation." Potentials for intergenerational conflicts may never be ruled out from families in which the acculturated girls unsettle the privileged discourse of patriarchal values; parents and children contribute to "A Tale of Two cities," or two contested worldviews; and second generation immigrants carve out identity trajectory and repertory incompatible with their parents' totalized primordial national origin identity. Evidently, children of immigrants who experience intergenerational conflicts and ruptured family ties are more than likely to be inaccessible to native practitioner/researcher in spite of or because of their parents' compensatory involvement in ethnic network or withdrawal from it.

Table. 1

\section{Identity Trajectory and Identity}

\begin{tabular}{|c|c|}
\hline Identity Trajectory & Identity Repertoire \\
\hline $\begin{array}{l}\text { Paradigm shift from less (unhyphenated } \\
\text { "Bangladeshi ") to more acculturated } \\
\text { (hyphenated "Bangladeshi-American” and } \\
\text { un-hyphenated “American/New Yorker") } \\
\text { identities through vertical substitution } \\
\text { similar to minimal pairs (beer, deer) }\end{array}$ & $\begin{array}{l}\text { Syntagmatic formulation of multiplex } \\
\text { identities ("Russian Doll,” "Juggler," } \\
\text { "Many Hats on the Same Head,” and } \\
\text { "Palimpsest not a Stone Tablet”) } \\
\text { characterized "by the ability to be } \\
\text { combined horizontally” (Bussmann, 1998) }\end{array}$ \\
\hline $\begin{array}{l}\text { The more acculturated identities are } \\
\text { incommensurate with the less acculturated } \\
\text { identities }\end{array}$ & $\begin{array}{l}\text { Multiple old and new identities are } \\
\text { processed simultaneously by code } \\
\text { switching among various subject positions }\end{array}$ \\
\hline Does not require complex repertory & Contingent upon extended trajectory \\
\hline Illustrated as a succession of vertical lines & $\begin{array}{l}\text { Illustrated as a horizontal line cutting } \\
\text { across the trajectory with a spiral going } \\
\text { from the beginning to the end }\end{array}$ \\
\hline
\end{tabular}


Table 2.

Typology of Acculturation Levels Reflecting the Ability to Embrace Difference

\begin{tabular}{|l|c|c|c|c|c|}
\hline $\begin{array}{c}\text { Level of } \\
\text { Acculturation }\end{array}$ & $\begin{array}{c}\text { Primary } \\
\text { Socialization }\end{array}$ & $\begin{array}{c}\text { Secondary } \\
\text { Socialization }\end{array}$ & Intentionality & $\begin{array}{c}\text { Identity } \\
\text { Trajectory }\end{array}$ & $\begin{array}{c}\text { Identity } \\
\text { Repertoire }\end{array}$ \\
\hline Minimal & + & - & - & - & - \\
\hline Moderate & + & + & + & + & - \\
\hline High & - & + & + & + & + \\
\hline
\end{tabular}




\section{References}

Alba, R. A., \& Nee, V. (2003). Remaking the American mainstream: Assimilation and contemporary immigration. Cambridge, MA: Harvard University Press.

Anderson, B. (1983). Imagined communities: Reflections on the origin and spread of nationalism. London: Verso.

Bussmann, H. (1998). Routledge dictionary of language \& linguistics. New York: Routlege

Foner, N. (2006, Winter/Spring). Then and now or then to now: Immigration to New York in contemporary and historical perspective. Journal of American Ethnic History. 33-47.

Fischer, M. M. (1986). Ethnicity \& the Arts of Memory. In J. Clifford \& G. E. Marcus (Eds.), Writing culture: The poetics and politics of ethnography (pp194-233). Berkley: University of California Press.

Gans, H. J. (2000). Filling in some holes: Six areas of needed immigration research. In N. Foner; R.G. Rumbaut \& S.T. Gold (Eds.), Immigration research for new century: Multidisciplinary perspectives, (pp. 76-89). New York: Russell Sage Foundation.

James, A., Hockey, J., \& Dawson, A. (1997). The road from Santa Fe. In A. James, A., J. Hockey \& Dawson, A. (Eds.), After writing culture; Epistemology and praxis in contemporary anthropology (pp. 1-15). New York: Routledge.

Johnson, B. (1982). The critical difference: Essays in the Contemporary rhetoric of reading. Baltimore: The Johns Hopkins University Press.

Kasinitz, P., Mollenkopf, J., Waters, C. \& Holdaway, J. (2008). Inheriting the city: The children of immigrants come of age. New York: Russell Sage Foundation.

Kasinitz, P., Mollenkopf, J., Waters, C. \& Holdaway, J. (2006). Becoming American/becoming New Yorkers: The second generation in a majority minority city. Migration information source: Fresh thought, authoritative data, global reach. Retrieved September 12, 2006, from http://migrationinformation.org/Feature/Display

Kasinitz, P. (2004). Race, assimilation, and second generation, past and present. In N. Foner \& G. Frederickson (Eds.), Not Just black and white: Historical and contemporary perspectives on immigration, race, and ethnicity in the United States. New York: Russell Sage Foundation.

Kasinitz, P., Mollenkopf, J.H., \& Waters, M. (2004). Becoming New Yorkers: Ethnographies of the new second generation. New York: Russell Sage Foundation. 
Kasinitz, P., Waters, M.C., Mollenkopf, J.H. \& Anil, M. (2002). Transnationalism and the children of immigrants in contemporary New York. In P. Levitt, \& M.C. Waters (Eds.), The changing face of home: The transnational lives of the second generation (pp. 96-122). New York: Russell Sage Foundation.

Kasinitz, P. (1992). Caribbean New York: Black immigrants and the politics of race. Ithaca, NY: Cornell University Press.

Krishna, S. (1999). Postcolonial Insecurities: India, Sri Lanka and the question of nationhood. Minneapolis: University of Minnesota Press.

Levitt, P., \& Schiller, N.G. (2004). Conceptualizing Simultaneity: A transnational social field perspective on society. International Migration Review, 38 (145), 595-629.

Levitt, P., \& Waters, M.C. (2002). Introduction. In P. Levitt, \& M.C. Waters (Eds.), The changing face of home: The transnational lives of the second generation (pp.130). New York: Russell Sage Foundation.

Massey, D.S. \& Denton, N.A. (1985). Spatial assimilation as a socioeconomic outcome. American Sociological Review, 59 (1), 94-106.

Minh-Ha, T.T. (1995). No master territories. In B. Ashcroft, G. Griffiths \& H. Tiffin (Eds.), The Post-Colonial Reader (pp. 215-218). New York: Routledge.

Mollenkopf, J. H. (2005, December). Trajectories of immigrant second generation in New York City. FRBNY Economic Policy Review, 1-6.

Mollenkopf, J.H. \& Casteles, M. (1991). Introduction. In J.H. Mollenkopf \& M. Castells (Eds.), Dual city: Restructuring New York (pp. 3-22). New York: Russell Sage Foundation.

Park, R.E., \& Burgess, E.W. (1924). Introduction to the science of sociology. Chicago: University of Chicago Press.

Portes, A. (2004). For the second generation, One step at a time. In T. Jacoby (Ed.), Reinventing the melting pot: The new immigrants and what it means to be American (pp. 155-166). New York: Basic Books.

Portes, A., \& Rumbaut, R. (2001). Legacies: The story of the immigrant second generation. New York: Russell Sage Foundation.

Portes, A., \& Zhou, M. (1993). The new second generation: Segmented assimilation and its variants. The Annals of the American Academy of Political and Social Science, 530, 74: 96.

Smart, B. (1997). Genealogy. In M. Payne, M. Ponnuswami, \& J. Payne (Eds.) A dictionary of cultural \& critical theory. p-218. New York: Blackwell. 
Waldinger, R. D. \& Feliciano, C. (2003). Will the next generation experience "downward assimilation?” Retrieved November 7, 2006, from

http://repositories.edlib.org/uclasoc/4.

Warner, W.L., \& Srole, L. (1945). The social systems of American ethnic groups. New Haven, CT: Yale University Press.

Zangwill, I. (1925). The Melting Pot. New York: Macmillian. 